\title{
Left atrial dissection: A multifaceted complication
}

\author{
Paolo Stassano, MD, ${ }^{a}$ Antonino Musumeci, MD, ${ }^{a}$ Luigi Di Tommaso, MD, ${ }^{\text {a }}$ and Paolo Pepino, MD, ${ }^{\text {b }}$ Naples and \\ Castelvolturno, Italy
}

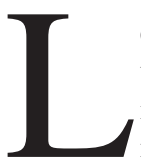

eft atrial dissection (LAD) is a rare complication that usually occurs after mitral valve replacement (MVR). It is an insidious complication that can present itself in many aspects that may confuse the clinical picture. ${ }^{1-4}$

\section{Clinical Summary}

On January 2005 a 64-year-old man was admitted to our hospital for fever. He underwent open mitral commissurotomy in 1980 and an MVR with a 33 Carpentier porcine bioprosthesis in 1995. A transesophageal echocardiogram (TEE) showed vegetation on the bioprosthesis and thrombi in the left atrium. At surgery, thrombi were removed from the left atrium, and the bioprosthesis was excised. At examination the prosthesis revealed vegetation and thrombi on the ventricular side. A 29 St Jude mitral prosthesis (St Jude Medical Inc, St Paul, Minn) was implanted by means of 2-0 Tevdek pledget-reinforced sutures. Intraoperative TEE showed good valve function and no periprosthetic leakage. In the afternoon of the second postoperative day, the patient had intense dyspnea and a systolic murmur was heard. TEE showed a well-functioning prosthesis, but there was a dissection of the posterior wall of the left atrium with systolic flow from the left ventricle into the left atrium far from the prosthesis (Figure 1, $A, B$ ). Immediate reoperation was planned. At surgery an intimal tear with irregular margins was found approximately $1.5 \mathrm{~cm}$ away from the prosthetic

From Cardiac Surgery, University Federico II, ${ }^{a}$ Naples, Italy, and Cardiac Surgery Clinica Pineta Grande, ${ }^{\mathrm{b}}$ Castelvolturno (CE), Italy.

Received for publication March 6, 2006; accepted for publication March, 15 2006.

Address for reprints: Paolo Stassano, MD, Via Bramante, 19, 81100 Caserta, Italy (E-mail: pstassano@libero.it).

J Thorac Cardiovasc Surg 2006;132:152-3

$0022-5223 / \$ 32.00$

Copyright (C) 2006 by The American Association for Thoracic Surgery doi:10.1016/j.jtcvs.2006.03.018 annulus between 6 and 9 o'clock. The St Jude prosthesis was intact, and there were no paravalvular leaks. The dissection was closed, gluing the margins and using 2-0 Tevdek pledget-reinforced sutures anchored to the ring of the mitral prosthesis, thus obliterating the false left atrial lumen (Figure 2, A). Intraoperative TEE showed closure of the dissection and absence of leakage around the prosthesis (Figure 2, B). The postoperative course was uneventful, and the patient was discharged 7 days later.

\section{Discussion}

Cardiac ruptures after MVR are located on the posterior wall of the left ventricle or in the atrioventricular groove; they are rare $(1.2 \%)$ and usually fatal. ${ }^{5}$ LAD is rarer $(0.8 \%)$ but can be successfully treated. ${ }^{1}$ Only a few cases have been described, with "chameleonlike" clinical aspects. ${ }^{1-4}$

LAD can appear after the first mitral operation, but also after redo MVR and after external cardiac massage in 1 patient after MVR. It has been reported after a transeptal mitral approach, but also after a normal left atrium entry. It can occur with the patient still on the operating table, in the early postoperative period, or months after surgery. The patient can be severely incapacitated or only mildly symptomatic with the dissection found only at echocardiogram. Dissection is usually located in the posterior wall of the left atrium, but a location in the interatrial septum has also been described. LAD usually occurs after surgery on the mitral valve, but can also occur after aortic valve replacement or mitral-aortic valve replacement. A calcified mitral annulus has been implicated in LAD, but LAD can occur with a normal mitral annulus. An excessive debridement of the mitral annulus has been thought to be responsible, but this complication also occurred when the posterior valve apparatus was left intact. LAD can be found after replacement of the mitral valve, but also after a mitral valve conservative surgery. LAD can occur when a mechanical prosthesis (rigid annulus) is used, but also when a biologic valve (more flexible ring) is used. An oversizing of the mitral prosthesis implanted has been deemed responsible, but LAD has also occurred when a

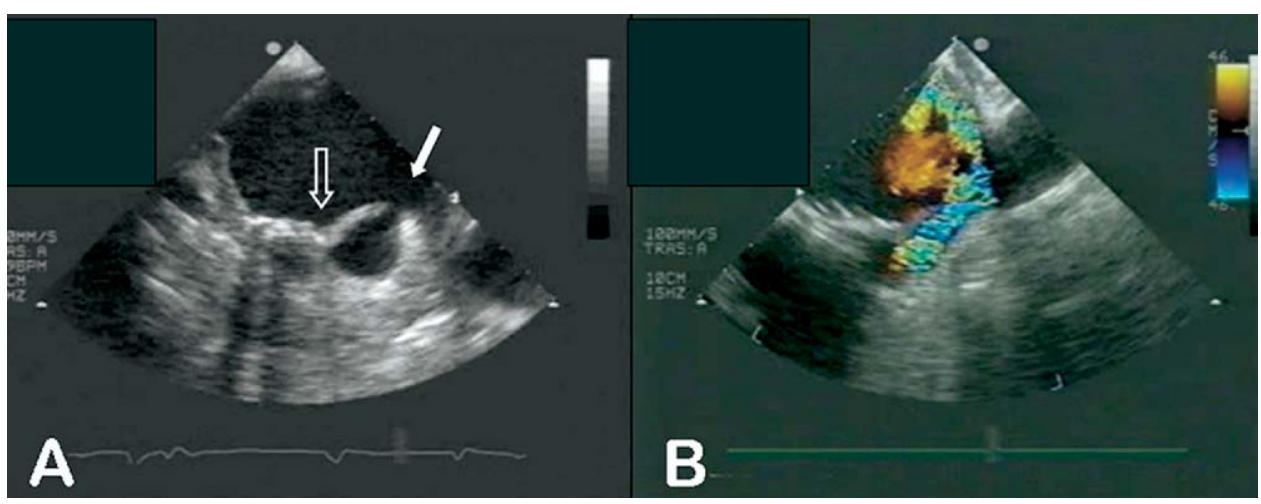

Figure 1. A, TEE. Dissection (full arrow); prosthesis annulus (empty arrow). B, Doppler color-flow shows the regurgitant jet onto the left atrium. 


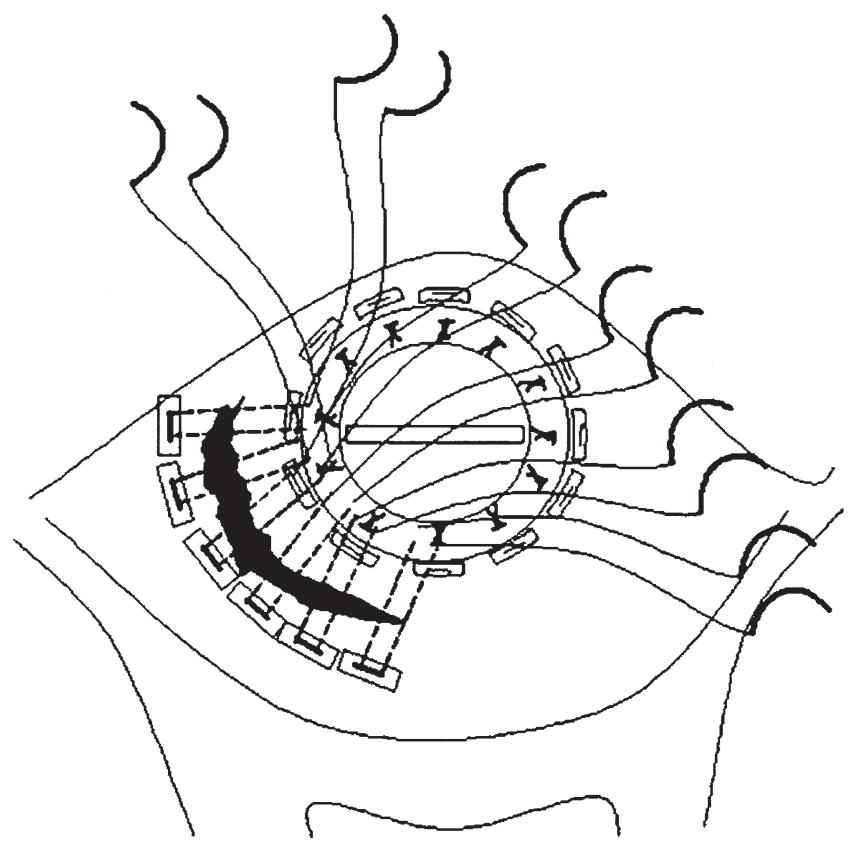

Figure 2. Reparative technique.

normal-sized prosthesis has been used. An overzealous thrombi removal has been implicated, but LAD has also been described when there were no thrombi in the left atrium. LAD can be the consequence of extreme tissue fragility in the case of multiple sclerosis or floppy mitral valve, but it has been found in patients with normal-appearing tissues. Endocarditis can be responsible, but LAD has been described in the absence of endocarditis. At the echocardiogram LAD can mimic a mitral insufficiency and an abnormal cavity protruding and compressing into the left atrium. Immediate surgical treatment may be undertaken, but it may also be left alone and periodically controlled. Surgical treatment requires closure of the dissection, but an internal drainage has been described.

From this confusing clinical picture we conclude that LAD must be suspected in every patient who does not improve after valve surgery or presents with clinical deterioration after an initial improvement. In these patients, TEE is always mandatory.

\section{References}

1. Martinez-Sellés M, Garcia-Fernandez MA, Moreno M, Bermejo J, Delcán JL. Echocardiographic features of left atrial dissection. Eur J Echocardiography. 2000;1:147-50.

2. Sekino Y, Sadahiro M, Tabayashi K. Successful surgical repair of left atrial dissection after mitral valve replacement. Ann Thorac Surg. 1996; 61:1528-30.

3. Ninomiya M, Taketani T, Ohtsuka T, Motomura N, Takamoto S. A rare type of left atrial dissection. J Thorac Cardiovasc Surg. 2002;124:618-20.

4. Osawa H, Yoshii S, Hosaka S, Suzuki S, Abraham SJK, Tada Y. Left atrial dissection after aortic valve replacement. $J$ Thorac Cardiovasc Surg. 2003;126:604-5.

5. Karlson KJ, Ashraf MM, Berger RL. Rupture of the left ventricle following mitral valve replacement. Ann Thorac Surg. 1988;46:590-97.

\section{Mild hypothermia $\left(32^{\circ} \mathrm{C}\right)$ and antegrade cerebral perfusion in aortic arch operations}

Farhad Bakhtiary, MD, Selami Dogan, MD, Omer Dzemali, MD, Peter Kleine, MD, PhD, Anton Moritz, MD, PhD, and Tayfun Aybek, MD, PhD, Frankfurt/Main, Germany

A ntegrade cerebral perfusion (ACP) has been popularized, offering a more physiologic method of perfusion and extending the safe limits for arch repair. ${ }^{1}$ Deep hypothermia has been used as an adjunct to ACP almost universally. The absolute necessity for deep hypothermia

From the Department of Thoracic and Cardiovascular Surgery, Johann Wolfgang Goethe University Hospital, Frankfurt/Main, Germany.

Address for reprints: Farhad Bakhtiary, MD, Department of Thoracic and Cardiovascular Surgery, Johann Wolfgang Goethe University, Theodor Stern Kai 7, 60590 Frankfurt/M, Germany (E-mail: farhad@bakhtiary.de).

J Thorac Cardiovasc Surg 2006;132:153-4

$0022-5223 / \$ 32.00$

Copyright () 2006 by The American Association for Thoracic Surgery doi:10.1016/j.jtcvs.2006.03.028 once ACP with flow rates and pressures within the physiologic range is provided has been questioned recently. Ehrlich and colleagues ${ }^{2}$ showed that brain oxygen consumption is reduced by $50 \%$ of baseline values if the patient is cooled systemically to $28^{\circ} \mathrm{C}$ core temperature. Yet the regional cerebral blood flow with antegrade perfusion decreases more rapidly at less than $28^{\circ} \mathrm{C}$ than between $36^{\circ} \mathrm{C}$ and $30^{\circ} \mathrm{C} .{ }^{3}$ Thus a perfusate temperature of greater than $28^{\circ} \mathrm{C}$ should be optimal for ACP to meet the lowered metabolic demands of the brain. By using this modified temperature management, the drawbacks of long cooling and rewarming periods on cardiopulmonary bypass (CPB) could be avoided. This article describes the operative management with this concept.

\section{Technique}

After systemic heparinization (300 IU/kg), the right subclavian artery is exposed through a 4-cm subclavian incision. Cannulation 